\title{
Improving public policy in the field of human resources reproduction as a regional sustainable development factor
}

\author{
Robert Akyulov*, and Elvira Nedorostkova \\ Ural Institute of Management -branch of RANEPA, Ekaterinburg, Russia
}

\begin{abstract}
The article explores demographic problems, such as birth rate decrease, high rate of mortality and structural unemployment in the RF regions through the example of a typical industrial territory - the Sverdlovsk region. The vital rate trends in the Sverdlovsk region are analyzed, where, since 2016, the growing population decline, demographic ageing and shrinking numbers of the economically active population have been observed. The reasons of the current demographic situation in the country and regions, having ample evidence of depopulation, are considered. Providing a simple population replacement mode, addressing social and demographic problems, necessary to increase human resources reproduction efficiency, are essential for the sustainable development of the regional economy. However, this can only be achieved through public administration system improvement and modern technologies implementation. It is proposed to increase the efficiency of interdepartmental interaction between healthcare, educational and labor institutions, which focus at birth rate increase, health improvement, education development, full population employment and provision of economic entities with qualified workforce. In addition, a set of measures is developed to combat depopulation and to improve human resources reproduction policy at the national and regional levels to provide for sustainable development.
\end{abstract}

\section{Introduction}

In the modern world, economic and social development prospects are determined by the significance the state and corporations attach to human resources, workers, their efficient development and use. The human factor has become a key strategic resource shaping socioeconomic development of the nations. Despite the technogenic development path, the increasingly spreading automation, digitalization and information technologies introduction, the role of an individual in the economy is growing, acquiring new forms as intellectual, organizational and creative abilities. Therefore, the stable population and human resources reproduction is essential for the economy and still appears relevant with years. Human potential development is gaining a transformational meaning, if compared to

\footnotetext{
${ }^{*}$ Corresponding author : akyulov_ri@mail.ru
} 
the "labour force" category used in the industrial period, becoming both an instrument for creating public good and a modern society progressiveness criterion, being at the same time a subject, a progress driver and an object, a consumer of the social production results. "Human resources are a key aspect of socio-economic development, prosperity and competitiveness of every region due to their contribution to the increased employment, job development and improved living standards of the residents". [1] Consequently, only efficient population and human resources reproduction is an essential condition for sustainable socio-economic development of the regions.

The currently observed depopulation and demographic ageing in the RF regions emphasize the importance of reproduction "of the population as an economic and social development factor, as the only source of the national labor resources, with the concern for its reproduction being one of the main functions of any state". [2, P.82]

\section{Research methodology}

It is widely known that human resources reproduction is an aspect of the population reproduction in general, consisting of a continuous process of population formation of a certain number, gender, age and social composition. Regulation of the population assumes government influence on changes in the demographic, economic and socio-professional structure, educational and cultural levels of the population, on migration and resettlement.

Considering the innovative development of economy and society, besides quantitative growth, the population reproduction implies also its quality changes. Post-industrial society predictably faces decreasing birth rate in the context of growing women's educational level and economic activity owing to their reducing need for children.

As the reproduction growth is ensured mainly through the birth rate intensity, such phenomenon as termination of pregnancy reduces the population growth prospects considerably. In this connection, it is important to note that over a long period of time Russia was the leader in the number of abortions per 1000 people. In recent years, the number of abortions has been decreasing steadily. However, by the percentage ratio of abortions number to the country's population, according to the AWR agency, in 2018, Russia was the 1st in the world: "1. Russia - 733,000 abortions (AWR data) - 0.50\%. 2. China - 6,800,000 (AWR data) - 0.48\%. 3. France - 203,000 (AWR data) - 0.31\%. 4. Vietnam - 275,000 (AWR data) - 0.29\%. 5. The US - 829,100 (AWR data) - 0.25\%. 6 . India - 794,000 (AWR data) - 0.06\%“. [3]

In this regard, it is necessary not only to pursue a family-centered public social policy, but also to reveal the potential reserves for fertility, both among the indigenous population of the RF regions and labor migrants, able to accept the culture, language, traditions and norms of behavior, assimilating into the Russian society. According to the research findings, there is "a higher overall abortion rate among the natives and illegal migrants, which emphasizes the importance of legal status, together with their other characteristics, for better understanding of reproductive behavior and more efficient relevant policy". [4]

In the same way, a number of specialists hold ambiguous veiws on migration, perceiving it as a negative factor for reproduction and rational human resources placement in case of dominating trend from rural areas and small towns into big cities - regional centers, which leads to depopulation of large territories, concentrating population in compact urban agglomerations. It is hard to disagree, as the uneven human resources settlement will constrain the large territories development, which, in turn, will hamper the national economy growth as a whole. Hence, maintaining migration balance in the regions and between urban and rural territories is estimated to be the most favorable for the regional socio-economic development. "To reach the zero migration balance, it is necessary to achieve an average wage of 30 thousand rubles, the number of individual enterprises 
should be 28.5 per 1,000 inhabitants. To considerably increase the population influx into rural areas the annual pay rise should be at least $10 \%$, and the number of sole traders per 1000 inhabitants should be no less than 29.6. [5, P.335]

At the same time, human resources reproduction cannot be limited only by quantitative growth, since the development of science, technology, modern production and other social activities depends on human development, that is, necessarily implies high-quality growth.

In recent years, the problem of mortality growth of the population of working-age, who are the basis of human resources, has gained global relevance. In addition, married people, having a family lifestyle, demonstrate greater vitality, resistance to disease factors and higher survival rates, which is proven by the specialist resarch findings indicating that marriage rate is inversely related with mortality. "The mortality rate of unmarried people, compared to those married, increased dramatically over the 1975-2008 period". [6, P.511]

The high mortality problem is of urgent concern in Russia, where deaths numbers reached 2,139 thousand people in 2020, very close to the maximum values of the indicator for 30 years, registered in 2002-2005.[9] This has a negative impact on the human resources reproduction results in the country and regions and will require comprehensive national measures to eliminate this trend and minimize its consequences for the economy.

"The problems of state regulation of the human resources reproduction field reflect the spontaneous nature of management entities actions leading to the persistently low productivity of human resources reproduction processes in the regions. Regions, as a kind of "junction" point, bear double responsibility (regional and federal components) for ensuring optimal conditions for human resources development, balanced numbers of jobs and specialists" [7, P.102] A well-developed concept of human resource reproduction management at regional level can be scaled, extended to all regions and the country in general. Therefore, first of all, it is worth considering the possibilities of the proposed comprehensive measures to improve the human resources reproduction efficiency at the regional level.

\section{Research findings}

The demographic situation can be analyzed through the example of a typical Russian region. Over the recent years, most Russian regions and typical, in this sense, Sverdlovsk region, in particular, demonstrates deteriorating demographic situation - decreasing birth rate, increasing mortality, continuing population ageing and in 2020 the negative impact of the pandemic caused by the COVID-19 virus (Table 1 ).

It is also important to mention, that the Sverdlovsk region, being a typical representative of the RF regions in almost all parameters, including demographic, social and labor, since 2016, has been undergoing a natural population decline of progredient nature. In 2017, the decline progressed 5 times, as compared to 2016, and in 2020 - more than twice, while the death rate exceeded the birth rate by over 1.5 times. Some experts are quite categorical in assessing the current situation in the Russian regions, arguing that "one of the most important family functions - reproductive - is also going through negative demographic changes. The downward trend in the birth rate in Russia has led to an emerged new social norm - childlessness." [8, P.57] 
Table 1. Dynamics of vital rate indicators of the Sverdlovsk region in 2008-2020.

\begin{tabular}{|c|c|c|c|c|c|c|}
\hline Years & $\begin{array}{c}\text { Births, } \\
\text { people }\end{array}$ & $\begin{array}{c}\text { Births, per } \\
1,000 \\
\text { population }\end{array}$ & $\begin{array}{c}\text { Deaths, } \\
\text { people }\end{array}$ & $\begin{array}{c}\text { Deaths, per } \\
1,000 \\
\text { population }\end{array}$ & $\begin{array}{c}\text { Natural } \\
\text { population } \\
\text { increase, } \\
\text { decline (-) }\end{array}$ & $\begin{array}{c}\text { Natural } \\
\text { population } \\
\text { increase, decline } \\
(-) \text { per } 1,000 \\
\text { population }\end{array}$ \\
\hline 2008 & 54364 & 12,6 & 64702 & 15,0 & -10338 & $-2,4$ \\
\hline 2009 & 56323 & 13,1 & 63045 & 14,6 & -6722 & $-1,5$ \\
\hline 2010 & 57540 & 13,4 & 61486 & 14,3 & -3946 & $-0,9$ \\
\hline 2011 & 58038 & 13,5 & 60814 & 14,1 & -2776 & $-0,6$ \\
\hline 2012 & 61649 & 14,3 & 60155 & 14,0 & 1494 & 0,3 \\
\hline 2013 & 62229 & 14,4 & 59266 & 13,7 & 2963 & 0,7 \\
\hline 2014 & 62600 & 14,5 & 60386 & 14,0 & 2214 & 0,5 \\
\hline 2015 & 62232 & 14,4 & 61222 & 14,1 & 1010 & 0,3 \\
\hline 2016 & 59840 & 13,8 & 60831 & 14,0 & -991 & $-0,2$ \\
\hline 2017 & 53386 & 12,3 & 57685 & 13,3 & -4299 & $-1,0$ \\
\hline 2018 & 50254 & 11,6 & 58511 & 13,5 & -8257 & $-1,9$ \\
\hline 2019 & 46039 & 10,7 & 57392 & 13,3 & -11353 & $-2,6$ \\
\hline 2020 & 44343 & 10,3 & 67381 & 15,7 & -23038 & $-5,4$ \\
\hline
\end{tabular}

Compiled by authors based on the given electronic resources: https://sverdl.gks.ru/folder/29698 https://www.e1.ru/news/spool/news_id-69792386.htm, https://www.e1.ru/news/spool/news_id69792563.html https://yandex.ru/turbo/oblgazeta.ru/s/society/119720/

Considering the number and structure of the economically active population of the Sverdlovsk region, the following changes occurred over 2016-2020 period. The number of labor force decreased from 2,230.1 million to 2,109.1 million people, by 5.5\%, having adverse effects on the development prospects of the labor market and the economy of the region as a whole.

As a consequence, it can be stated that in recent years, the Sverdlovsk region, as most other regions, has been sufferring a negative trend towards a decrease in the population and human resources made up of economically active population and those under the working age, which is largely due to the ineffective regulation of human resources reproduction on behalf of the public administration system. Official figures show that "the resident population of Russia as of January 1, 2021, according to Rosstat estimates, was 146.24 million people, which is 510 thousand people less than of January 1, 2020 (146.75 million people). Even greater reduction was observed in Russia as of 2005 year-end - when the country's population decreased by 564.5 thousand people. Thus, the country's population decline in 2020 pandemic year set a 15 year record". [9]

Experts offer various methods aimed at increasing efficiency of state regulation of the social and labor fields of the country and regions. At the same time, a systematic approach to managing human resources reproduction at the regional and national levels is poorly developed. Hence the dismal results starting from 2020, which has become the year of antirecords, especially in terms of demography.

The main reasons for such a disastrous condition is the low level of the health care system development, in particular, as a result of the recent optimization followed by a reduction in the numbers of medical and prophylactic institutions. In addition, there is a 
shortage of doctors and nurses, especially in regions and remote areas, as well as a drop in living standard and an increased proportion of those living below a minimum subsistence income.

\section{Discussion}

Under the current complex geopolitical conditions and in the context of the ongoing pandemic caused by the COVID-19 virus, the unfavorable socio-economic and demographic conditions are observed in the Russian regions, which is partly due to the low efficiency of the public administration, the reforming potential of which looks vague and causes justified skepticism among many experts. Nevertheless, opportunities are yet to be found to improve the regulatory impact on the social sphere, population reproduction, labor market, providing employment or social benefits to the economically active population. Here, important is the experience of the developed European nations, which also have to address problems referring to the market nature of the economy, while applying complex regulatory measures.

Foreign experts also emphasize the human resources reproduction, understanding it as social reproduction and as "an activity contributing to the future workers development, restoring the current workforce and supporting those who cannot work, i.e., a set of tasks which altogether support and reproduce life, both currently and through generations. Social reproduction consists, broadly, of direct self-concern and caring for others (childcare, elderly care, healthcare), maintaining physical space and organizing resources as part of an indirect process of caring for oneself and others (cleaning, shopping, repairing) reproduction of species (birth of children)".[10, P. 338]

The developed nations also face problems of human resources reproduction, especially in terms of training, distribution and effective use. These are, for example, structural unemployment, skilled workers shortage in certain industries. In France, in particular, the government is forced to solve the problem of highly qualified personnel training to meet the needs of manufacturers, especially those involved in the innovative business. Foreign experts describe the current situation, where the cause of the problem is in "massive discrepancy between the demand for workers with the required competencies and the available unemployed lacking these skills. France just does not produce the number skilled workers it currently needs. This means that even though the country has shown the strongest growth over 6 years, a skilled workerforce shortage creates bottlenecks in production and obstructs supply chains". [11] "Considering the fact that in the medium term "as a result of robotization processes, large numbers of people will lose their jobs, first of all, in industrial production, retail trade, transportation, public administration, agriculture, construction" [12, P. 35], the next problem will be the need for redundant workers retraining and their acquiring of qualifications for the new types of activities.

To minimize demographic problems and increase human resources reproduction efficiency, a broader and more active introduction of modern management technologies, with the proven efficiency in business and entrepreneurial activity, into public administration is essential. In the field of human resources reproduction, such technology as management by results seems useful, that of a cyclical nature and unlimited in time, it fully addresses the endlessly arising complex issues connected with creation and provision of favorable conditions for the birth of new generations, their upbringing, education, choice of profession and activity, efficient employment, for entrepreneurial activity and social protection of vulnerable groups.

In addition to modern management technologies, regional human resources and population marketing should be employed more extensively, to achieve a balance of the needs of the state, the economy for a competitive labor force and on the other hand - 
economic, social and spiritual needs of the population. "Achieving such a balance is possible only through modern management technologies which require investment in an individual, who is both a subject and an object of management, aiming at improving their quality and, consequently, the competitiveness of the population and the national economy". [13, p.86].

The assessment of efficiency of socio-economic policy in the field of human resources reproduction should involve identification of profitability level, i.e. the ratio of expenditures and incomes and the social effect, measured not much in value terms, but in such indicators as quality of life, social stability in the region, which should ensure its sustainable development.

\section{Conclusion}

The human resources reproduction management system improvement implies an increased efficiency of all stages of the reproduction cycle. From the production stage, defined by the fertility processes characteristics, through the exchange and redistribution stage, determined by socialization, education and professional training, to the use and restoration stage, which provides for ensuring efficient employment, creating conditions for labor productivity improvement, and enhancing the volume and quality of produced public goods, prolonging the life and labor activity of the population. For that, a methodology is required to assess and monitor the target indicators parameters, set while developing the long-term programs at intermediate stages in the form of control indicators.

Thus, main directions for improving public policy in the field of human resources reproduction to ensure sustainable development of the region can be outlined in the following way:

1) elaboration and implementation of the general education system development programs for children of preschool and school age, providing available kindergartens and schools for young families with children, establishing intellectual, spiritual and traditional culture with reference to regional specifics;

2) providing social and financial support to families with children and promoting family and healthy lifestyles, responsible motherhood and parenthood for all age groups, advancing these values in the media;

3) the regional public youth policy improvement, providing opportunities for the comprehensive development of young people, regardless of the social group income level, accessing sports, cultural, artistic, musical, choreographic activities, engineering and design, promoting the value of life and health in the mass consciousness of the population;

4) developing the system of higher, secondary vocational, additional education, creating conditions for continuous advanced staff training and through the entire career, with reference to the changes in the regional labor market;

5) rationalization of forms and methods of the regional human resources distribution, developing an effective employment system, contributing to growth in income of the economically active population, level and quality of life, construction of affordable and quality housing, multi-level education and modern healthcare development.

\section{References}

1. D. Jašková, K. Haviernikova, The Human Resources as an Important Factor of Regional Development, International Journal of Business and Society, 21 (3), 14641478 (2021) 
2. E.M. Kozakov, R.I. Akyulov, A.Yu. Berdnikova, Using of econometric methods for researching the economic and demographic development of the territory, Izvestiya USUE, 1 (23), 81-85 (2009)

3. Anti-demographic statistics: Russia remains the world leader in abortions number, RIA Katyusha (2019). Access mode: http://katyusha.org/view?id=12634

4. V. Agadjanian, S. H. Yoo, Migration, legality, and fertility regulation: Abortion and contraception among migrants and natives in Russia, Demographic research, 38, 1277-1302 (2018)

5. I. Mukhina, G. Ostaev, V. Sokolov, E. Markovina, Migration processes in rural areas as an indicator of economic security, AMAZONIA INVESTIGA, 9 (28), 330-337 (2020)

6. Q. Kravdal, E. Grundy, K. Keenan, The increasing mortality advantage of the married: The role played by education, Demographic research, 38, 471-512 (2017)

7. R. I. Akyulov, Socio-economic criteria and indicators of human resources reproduction in the region, Management issues, 4 (21), 102-105 (2012)

8. O. I. Donina, A. Salikhova, I. V. Aryabkina, M. A. Kovardakova, Yu. A. Chernova, Normative models and trends in the development of intra-family relations in modern conditions, AMAZONIA INVESTIGA, 10 (38), 51-58 (2021)

9. In the context of pandemic the RF population decline hit the record high over 15 (2021). Access mode:

https://www.rbc.ru/economics/28/01/2021/6012a7ca9a7947d4e0e8042d

10. The Crisis of Social Reproducction and the End of Work, The Age of Perplexity.

Rethinking The World we knew (Madrid: BBVA, OpenMind, Penguin Random House Grupo Editorial, 2017)

11. T. Leigh, As France's economy takes off, a new problem: labor shortages, REUTERS 9.02.2018 (2018). Access mode: https://www.reuters.com/article/us-france-economylabour-idUSKBN1FT2KG

12. R. I. Akyulov, A. A. Skovpen, The role of artificial intelligence in the transformation of the modern labor market, Discussion, 3 (94), 30-40 (2019)

13. R. I. Akyulov, Modern management and marketing tools in municipal management, Municipality: Economics and Management, 4 (9), 85-90 (2014) 